\title{
DA “CULTURA" DO MARXISMO A UM MARXISMO DA CULTURA: ALGUMAS NOTAS SOBRE PÓS-MODERNISMO E UTOPIA EM FREDRIC JAMESON
}

Hyury Pinheiro*

\begin{abstract}
Resumo: Apresentam-se aspectos críticos da análise de Jameson sobre o pósmodernismo, a fim de apontá-la como resultante da tentativa teórica de considerar a cultura a partir de uma matriz marxista. Discute-se ainda o viés emancipatório dessa análise, que traz novidades teórico-práticas ao marxismo. Para isso, apresentase breve panorama do movimento teórico realizado dentro do marxismo que busca apreender a cultura como objeto. Na sequência, expõe-se em linhas gerais a noção crítica de Jameson sobre o pós-modernismo e o lugar da utopia, identificando sua originalidade e a proficuidade da teoria marxista em analisar a cultura.
\end{abstract}

Palavras-chave: Marxismo; Cultura; Pós-modernismo; Utopia.

From the "culture" of marxism to a marxism of the culture: some notes about postmodernism and utopia in Fredric Jameson

\begin{abstract}
It intends to present critical aspects of Jameson's analysis of postmodernism in order to link this analysis as a result of the attempt to consider the culture from a Marxist matrix. It discusses the emancipatory bias in this analysis, which provides theoretical and practical innovations to Marxism. For this it puts up brief overview of moments from the theoretical movement performed within Marxism, which seeks to grasp the culture as object. After that, it is exposed the Jameson's critical notion on postmodernism and the place of utopia, thus identifying its originality and usefulness of Marxist theory to analyze the culture.
\end{abstract}

Keywords: Marxism; Culture; Postmodernism; Utopia.

\footnotetext{
* Instituto de Filosofia e Ciências Humanas, Universidade Estadual de Campinas - Unicamp, Campinas-SP, Brasil (hyure.pnh@gmail.com).

Recebido em: 30/11/2014 - Aceito em: 11/08/2015.
} 
De la "cultura" del marxismo a un marxismo de la cultura: algunas notas sobre posmodernismo y utopía en Fredric Jameson

Resumen: El objetivo es presentar aspectos críticos del análisis de Jameson del pósmodernismo con el fin de vincularlo al intento teórico de considerar la cultura desde una matriz marxista. Se discute la connotación emancipadora de este análisis, que trae innovaciones teórico-prácticas al marxismo. Presentase así breve panorama de los momentos del movimiento teórico realizado en el marxismo que busca aprender la cultura como un objeto. Después se expone de forma general la noción crítica de Jameson sobre el posmodernismo y el lugar de la utopía. Identificase así su originalidad y la utilidad de la teoría marxista en el análisis de la cultura.

Palabras clave: Marxismo. Cultura. Posmodernismo. Utopía.

\section{Introdução}

No século $X X$, a questão da cultura se constituiu como uma controvérsia teórica dentro do pensamento marxista. Essa controvérsia construiu um rico painel de possibilidades analíticas, a partir das quais se vislumbraram novidades teóricas e práticas. Essas novidades consolidaram, entre outras coisas, aquilo que Anderson (1976) chamou de "marxismo ocidental"1. Os novos diagnósticos de época que daí surgiram mobilizavam elementos teóricos que se colocavam além das considerações econômicas e político-partidárias, sem, contudo, as negar. A análise que Fredric Jameson (1934-) nos proporciona é um exemplo disso, na medida

\footnotetext{
${ }^{1}$ Esse termo designa uma nova configuração de temas e problemas de um conjunto de intelectuais marxistas causada, em grande medida, pelas transformações políticas e econômicas que tomaram a Europa na primeira metade do século XX. Há em comum entre esses intelectuais o ponto de partida, i.e., o marxismo, e a transformação de suas preocupações políticoteóricas nesse período. Mas isso não significa que o conteúdo dessa nova configuração seja uno para esses intelectuais: apesar de se colocarem, em geral, problemas referentes ao papel da consciência na práxis, apresentam especificidades em função de sua geração e localização geográfica. Dentre os intelectuais situados no "marxismo ocidental" estão Lukács, Gramsci, Horkheimer e Adorno (ANDERSON, 1976: 37-38).
} 
em que aparece como um resultado dessas controvérsias teóricas que se deram ao longo do tempo.

O objetivo desse artigo é apresentar, de modo geral, a análise de Jameson enquanto novo momento de um movimento teórico realizado dentro do "marxismo ocidental", cujo motor é a controversa consideração da cultura enquanto elemento significativo para a análise social. Essa análise será exposta a partir de algumas de suas considerações acerca da questão do pós-modernismo, de modo que não se pretende apresentar exaustivamente seu juízo sobre esse fenômeno, mas apenas utilizálas como meio para expor alguns elementos teóricos inovadores resultantes dessa controvérsia.

Primeiro será apresentado um pequeno panorama que pretende apresentar alguns elementos constitutivos dessa controvérsia, para depois entrar nas questões propostas por Jameson, apontando a conexão dessa proposta analítica a um movimento teórico mais geral, o "marxismo ocidental". Espera-se com isso demonstrar tanto a originalidade de sua análise quanto as possibilidades teóricas do "marxismo ocidental" com relação à cultura, que extrapolam os limites da "cultura" marxista, ou seja, vão além de certa visão economicista e/ou estrutural-partidária de análise social.

\section{Considerações gerais sobre a controvérsia da cultura no "marxismo ocidental"}

Marx e Engels não se detiveram sistematicamente em problemas que envolvessem a cultura como um objeto analítico primário. Isso somado à célebre assertiva que estabelece que a superestrutura seja determinada, em última instância, pela infraestrutura ${ }^{2}$, causou, nas formulações teóricas da maioria dos

2 "O conjunto [dessas] relações de produção constitui a estrutura econômica da sociedade ('ökonomische Struktur der Gesellschaft'), a base real sobre a qual se eleva uma superestrutura ('Überbau') jurídica e política e à qual 
chamados marxistas ${ }^{3,}$ uma relegação da cultura ao segundo plano em suas reflexões. Ao se apegar a essa relação de determinação unilateral, tende-se a dar razão a essa postura na medida em que a cultura, alocada na superestrutura, seria determinada pela dinâmica da infraestrutura econômica, sendo bastante para o tratamento da cultura a investigação da lógica do funcionamento econômico.

Contudo, alguns intelectuais marxistas, em especial os "ocidentais", demonstraram com suas pesquisas que tal leitura da obra de Marx é restrita e reducionista, uma vez que a relação dialética entre infraestrutura e superestrutura não é tomada no seu rigor, como uma relação total que encerra na unidade a contradição, de modo que ambos os momentos se determinam mutuamente. A partirdisso, oestudodacultura nomeiomarxistanãosófoi possível como se revelou necessário, já que analiticamente a cultura deixara de ser mero produto das relações sociais de produção e passou a ser, também, produtora dessas relações. Vislumbrou-se assim uma possibilidade real de apreensão crítica das relações sociais, apontando a impossibilidade de uma análise social totalizante que

correspondem formas sociais determinadas de consciência. O modo de produção da vida material condiciona o processo de vida social, política e intelectual. Não é a consciência dos homens que determina a realidade ('ihr Sein'); ao contrário, é a realidade social ('ihr gesellschaftliches Sein') que determina sua consciência." (MARX, 1988: 82-83). No original (MARX, 1971:89), podemos perceber que as categorias "Sein" (ser) e "gesellschaftliches Sein" (ser social) são traduzidas, respectivamente, por "realidade" e "realidade social". A frase "não é a consciência dos homens que determina o seu ser; ao contrário, é o seu ser social que determina sua consciência" tem um sentido bem diferente que o apresentado na citação, já que o ser social carrega toda uma problemática que transcende a noção de realidade enquanto algo apartado e oposto à consciência. Para maiores desenvolvimentos sobre essa questão, ver Lukács (2012).

${ }^{3}$ Como Engels, Kautsky e Plekhanov, entre outros (ANDERSON, 1976: 16). Ao citar esses três autores pretende-se apenas apontar um círculo intelectual a partir do qual se pode observar essa interpretação. 
negue o imbricamento e a multi-determinação entre infraestrutura e superestrutura.

Para que essa concepção pudesse ser desenvolvida, a ideia de determinação teria de ser trabalhada a fim de que se refutasse um entendimento teórico hostil à abordagem da cultura. Williams (1979: 87-92), a partir de uma análise etimológica e conceitual da ideia de "determinação" em Marx e Engels, pôde desenvolver um sentido diverso desse conceito que se apresentava como unilinear, sendo assim um produto de uma concepção reducionista da dialética marxista. Para ele, "determinação" não implica em relação de causalidade direta entre uma esfera e outra da sociedade, mas em "estabelecer limites" (determinações negativas) e pressões (determinações positivas) ${ }^{4}$. Disso entende-se que a sociedade, para além de ser um invólucro limitador de uma consciência maleável, é um processo constitutivo no qual coagem pressões derivadas de formas políticas, culturais e econômicas, as quais se internalizam na consciência dos sujeitos e constituem a "vontade individual" (WILLIAMS, 1979: 91). Ou seja, a sociedade - enquanto processo - constitui o indivíduo e é constituída por seus atos sociais. Desse modo, é possível pensar que as ações "superestruturais" individuais ou coletivas, têm o poder de influir sobre os limites estabelecidos pelas relações sociais de produção, sem perder de vista que tais ações se dão nos termos da vida material. É como escreveu Engels a Bloch: "Nós mesmos fazemos a história, mas, em primeiro lugar, sob pressupostos e condições muito definidas" (WILLIAMS, 1979: 89).

4 “Em todo um processo social, essas determinações positivas, que podem ser experimentadas individualmente, mas que são sempre atos sociais, na verdade com frequência formações sociais específicas, têm relações muito complexas com as determinações negativas que são experimentadas como limites. Pois elas não são apenas pressões contra os limites [...]. São no mínimo também pressões derivadas da formação e do impulso de um determinado modo social [...]. São também, e vitalmente, pressões exercidas por formações novas, com suas intenções e exigências ainda não percebidas." (WILLIAMS, 1979: 91) 
Essa possibilidade de ação efetiva de indivíduos ou coletivos no plano da cultura, do ponto de vista do seu impacto sobre a ordem capitalista, pode contribuir também para o seu intensivo aprofundamento, de modo a engendrar formas de dominação cada vez mais rígidas. Isso porque a sociedade capitalista é uma forma de sociedade baseada na lógica do fetichismo da mercadoria (MARX, 1985: 70-78), que "distorce" a realidade apreendida pela consciência através de um processo de reificação das relações humanas. Ou seja, a realidade social aparente resultante da mercadorização dessas relações dificulta a assimilação de uma realidade essencial ${ }^{5}$. Assim, as ações que se dão no plano da cultura podem refletir também a reificação da consciência, reproduzindo e intensificando aquelas formas de dominação.

Nesse sentido, Adorno e Horkheimer (2006) demonstraram em "A indústria cultural" que os elementos culturais identificados como capazes de causar distorções nos limites fixados pela vida material, tornaram-se mercadorias em função da capacidade da sociedade capitalista de incorporar, em seu favor, a sua própria negação. Assim, na cultura contemporânea (o texto é originalmente escrito em 1944), submetida ao sistema do capital e caracterizada pelo processo de mercadorização dos seus produtos, a obra de arte (seja musical, plástica, audiovisual, etc.) tomaria a forma de mercadorias culturais padronizadas, adquirindo assim a possibilidade de ser reproduzida. Esse tipo de cultura produzida em série é o que ficou conhecida como "cultura de massas" e pode ser enxergada como um mercado consumidor racionalmente estratificado em função dos nichos de demanda,

\footnotetext{
5 “Na consciência humana o mundo aparece completamente diverso daquilo que na realidade é: aparece alterado na sua própria estrutura, deformado nas suas efetivas conexões. Torna-se necessário um trabalho mental de tipo completamente particular para que o homem do capitalismo penetre nesta fetichização e descubra no interior das categorias reificadas (mercadoria, dinheiro, preço, etc.) que determinam a vida cotidiana dos homens, a verdadeira essência delas, de relações sociais, relação entre homens" (LUKÁCS, 1968: 23).
} 
abastecido por uma produção racionalizada de acordo com pesquisas de mercado, submetendo a produção cultural à lógica da concorrência. Toda essa padronização cultural remete à atrofia da imaginação e da espontaneidade ${ }^{6}$ das pessoas, à naturalização da rotina, à resignação. Além disso, a indústria cultural preenche o tempo e os sentidos dos consumidores de modo útil à ordem estabelecida, de modo a esterilizar, o quanto mais possível, as influências emancipatórias da cultura sobre as determinações materiais. Nesse sentido, Adorno e Horkheimer fazem uma distinção entre cultura como "arte" (aquela que provoca uma diferenciação das consciências; que gera uma tensão entre obra e cotidiano; que questiona a sociedade reificada) e como "negócio" (produção cultural padronizada e em série; racionalizada de modo a atingir o grande público; uniformizadora das consciências), de modo que o que é produzido dentro dessa lógica capitalista contemporânea (cultura de massas) torna-se negativo, e o que é produzido sem responder a ela ("alta" cultura), positivo. Decorre disso a compreensão de que a crítica seria produzida entre os membros da classe dominante, onde a "alta" cultura encontraria seu "habitat".

Jameson (1995: 14) se contrapõe a essa ideia valorativa binária entre cultura de massa/alta cultura, estabelecendo, entre os termos, uma relação objetiva e dialeticamente interdependente: uma relação pautada em "uma contradição objetiva, com o seu próprio fundamento social". Para isso ele considera a ideia de que a cultura de massa, ou melhor, popular do passado seria a alta cultura no presente e, por conseguinte, a cultura de massa contemporânea poderia se tornar a alta cultura futura; em outras palavras, não há como imputar uma classificação à cultura passada em função de uma distinção realizada no presente. Assim, “[...] a única forma

\footnotetext{
${ }^{6}$ Vale aqui um parêntese: a espontaneidade foi uma das vias emancipatórias propostas pelos situacionistas da década de 1960, através das quais seria possível se libertar das amarras de um cotidiano reificado. Para entender essa proposta, é interessante o "Manifesto Internacional Situacionista" de Debord (disponível em: <http://goo.gl/WnsKuJ> Acesso em jul. 2015).
} 
de 'alta cultura' que pode ser vista como oposto dialético da cultura de massa é a alta produção cultural contemporânea, vale dizer, a produção artística geralmente designada modernismo" (JAMESON, 1995: 15).

Sendo dialética essa oposição, cultura de massas e modernismo formam uma unidade contraditória, na medida em que a primeira está ligada à repetição e padronização ("função ideológica"), enquanto a segunda está ligada à inovação ("função utópica"). A repetição não sobrevive sem a inovação, e vice-versa, posto que é a partir da repetição que se tem a inovação (método de tentativa e erro, por exemplo) e é a partir da inovação que se tem repetição (já que uma vez que a inovação se estabelece, ela é reproduzida). Dada essa unidade contraditória, a cultura teria um duplo aspecto: 1 - ela administra e recalca os sentimentos através da sua padronização e constância, bem como mistifica a realidade, tendo caráter ideológico; e 2 - ela exprime a angústia e imaginação social de uma sociedade de modo a possibilitar a desmistificação da realidade, quebrando o padrão rotineiro e resignado do cotidiano reificado, apresentando, assim, um caráter utópico.

Percebe-se que esse modo de compreender a relação entre alta cultura e cultura de massas apresenta condições de admitir a reflexão de Williams (1979) sobre a ideia de "determinação", possibilitando uma teorização marxista em que o indivíduo ou o coletivo produtor de cultura seja investido de agência, para além de ser um mero produto das estruturas postas. Essa percepção de cultura ganha novas possibilidades políticas, e se afasta daquela percepção de Adorno e Horkheimer (2006) que postularia, justamente, o estrangulamento dessas possibilidades. Portanto, seria possível vislumbrar uma utopia revolucionária mesmo de dentro de um sistema social que se mostra cada vez mais sedimentado, rígido e hostil a mudanças. Tal posicionamento concretiza-se a partir de uma teoria marxista da cultura que vem se desenvolvendo a partir da crítica teórica do próprio marxismo - da qual o "marxismo ocidental" é momento crucial - e, mais importante, a partir da crítica da realidade social capitalista. Com isso, passamos às considerações de Jameson acerca do 
pós-modernismo, às quais esse primeiro momento do texto serviu de introdução.

\section{Possibilidades críticas em Jameson: algumas considerações sobre pós-modernismo e utopia}

Nesta seção serão expostas algumas considerações críticas de Fredric Jameson sobre o assim chamado pós-modernismo e o lugar da utopia nessa reflexão. Pretende-se com isso apontar uma abordagem teórica interessante do ponto de vista de sua riqueza para o tratamento dos fenômenos culturais - bem como do ponto de vista de uma crítica social construída a partir desse tratamento -, que se apresenta como uma resultante daqueles movimentos teóricos a que fizemos referência. Não se busca, contudo, demonstrar essa riqueza a partir do mapeamento da produção teórica influenciada pela abordagem jamesoniana, mas sugerir, a partir da incursão do autor no problema da pós-modernidade, as possibilidades críticas que surgem desta perspectiva.

No capitalismo tardio, fase do capital que representa uma ruptura com o imperialismo ou estágio do monopólio, segundo colocação de Ernest Mandel em "O capitalismo tardio"7, assiste-se

${ }^{7}$ Mandel (1982: 83) trabalha com a ideia de que o capitalismo aparece como uma "sucessão de movimentos cíclicos a cada 7 ou 10 anos" - cuja ascendência e descendência se dão em função do aumento ou diminuição do ritmo da acumulação de capital, sendo que esse ritmo é explicado tanto pela produtividade do trabalho quanto pela expansão do comércio mundial e como "uma sucessão de períodos mais longos, de aproximadamente 50 anos", marcados pelas transformações materiais qualitativas na forma de produzir, que, por alterarem a produtividade do trabalho, têm relação com aqueles movimentos cíclicos econômicos. Ele cita 4 longos períodos que abrangem a aplicação generalizada na produção industrial dos avanços proporcionados pelas 3 grandes revoluções tecnológicas: a máquina a vapor, os motores elétricos e a combustão e o controle de máquinas através da eletrônica. O mais importante aqui é notar que, como aponta Singer (1982: xx), "Mandel deduz as características do capitalismo tardio em grande parte do que chama 
ao predomínio daquilo que Jameson chama de "pós-modernismo", entendido não como estilo, mas como "um período histórico que decorre de um momento de ruptura na própria estrutura do capitalismo mundial" (CAMARGO, 2006: 129), como uma "dominante cultural" (JAMESON, 1997: 29). Entende-se assim que o capitalismo, enquanto modo de produção cuja centralidade esteja na categoria mercadoria, ainda não foi superado, mas sofreu mutações (CAMARGO, 2006: 132). Isso significa que, para Jameson, o pós-modernismo não existe em um mundo onde o modo de produção capitalista e as categorias que o expressam teoricamente, como mercadoria e luta de classes, foram superados. Com efeito, as teorias do pós-moderno propugnam - enquanto "missão ideológica" - o início de uma nova sociedade, de tipo "pósindustrial", como exposto por Daniel Bell, cuja formação não mais responde ao paradigma da produção industrial (JAMESON, 1997: 29). Jameson entende, pelo contrário, que a dialética utilizada por Marx para desvelar a lógica do sistema social que se desenvolvia em meados do século XIX continua útil para compreendermos a lógica do capitalismo atual que, embora tenha sofrido transformações formais, permanece em sua essência (JAMESON, 2001: 95).

Tais transformações dizem respeito a um novo estágio em que

[...] a própria esfera da cultura se expandiu, coincidindo com a sociedade de consumo de tal modo que o cultural já não se limita às suas formas anteriores, tradicionais ou experimentais, mas é consumido a cada momento

de terceira revolução tecnológica [...]", como por exemplo a redução da vida útil do capital fixo, aceleração do ritmo das inovações tecnológicas e a orientação do capital excedente para a indústria bélica. Caracteriza-o ainda "a concentração e centralização internacionais do capital que dá origem à empresa multinacional como a mais importante forma fenomênica do capital" (MANDEL, 1982: 4). Tais características demonstram a tendência do capital a manter sua existência - a despeito das constantes e crescentes crises do sistema econômico capitalista - através de pequenas "reinvenções" do seu modus operandi, que de modo algum alteram sua essência. 
da vida cotidiana, [...] em todos os pormenores do cotidiano. (JAMESON, 2001: 115, grifo nosso).

Aqui aquela distinção entre alta cultura (obra de arte autônoma) e cultura de massas (subordinada à indústria cultural) proposta por Adorno e Horkheimer em "Dialética do Esclarecimento" se dilui nesse novo momento do capitalismo. A lógica da produção cultural coincide, agora, com a lógica da produção de mercadorias, sendo que ambas se imbricam e se confundem (JAMESON, 1997: 30). O fundamento da não vigência daquela distinção é a concepção de capitalismo tardio utilizada e o paradigma histórico apreendido: Adorno e Horkheimer, olhando para o capitalismo dos anos 1940, pensam na cultura enquanto dominação a partir do desdobramento de uma crítica da razão instrumental e da noção pollockiana de capitalismo de estado ${ }^{8}$ ou monopolista (CAMARGO, 2006: 129); já Jameson, analisando a dinâmica que o capital assume a partir dos anos 1960, e entendendo que se trata de um capitalismo tardio mandeliano", ou seja, uma terceira fase da história do capitalismo onde o capital adquire formatação multinacional, pensa nessa dominação a partir de outro paradigma histórico. Esse novo paradigma exprime um capitalismo que "elimina os enclaves da organização pré-capitalista que ele até agora tinha tolerado e explorado de modo tributário" e realiza um novo movimento, qual seja "a penetração e colonização do Inconsciente e da Natureza" (JAMESON, 1997: 61). Assim, observa-se a tecnologia intervindo tanto nas questões ambientais,

Diante do diagnóstico do declínio da economia de mercado, Friedrich Pollock sugere uma economia capitalista planificada e administrada pelo Estado, a qual poderia assumir uma forma democrática ou totalitária. Para maiores detalhes ver Pollock (1990).

${ }^{8}$ Diante do diagnóstico do declínio da economia de mercado, Friedrich Pollock sugere uma economia capitalista planificada e administrada pelo Estado, a qual poderia assumir uma forma democrática ou totalitária. Para maiores detalhes ver Pollock (1990).

${ }^{9}$ Ver nota 7.

Idéias - Rev. Inst. Filos. Ciênc. Hum. UNICAMP, v.7, n.1, p. 227-248, jan/jul. 2016 
através da Revolução Verde, quanto na cultura, através da mídia e da indústria de propaganda (JAMESON, 1997: 60).

Se for certo que, a partir do momento em que não se consegue distinguir a esfera da cultura da do consumo, torna-se possível pensar em um processo de extinção da cultura, então não faria mais sentido tratar as produções culturais como mercadorias, em todo seu rigor conceitual, ao invés de teorizar a cultura? Para Jameson, essa questão se resolve no caminho inverso da extinção, ou seja, no caminho da afirmação da cultura enquanto objeto necessário e enriquecedor da análise teórica social. Há uma "dissolução da esfera autônoma da cultura" que

deve ser antes pensada em termos de uma explosão: uma prodigiosa expansão da cultura por todo o domínio do social, até o ponto em que tudo em nossa vida social - do valor econômico e do poder do Estado às práticas e à própria estrutura da psique - pode ser considerado como cultural, em um sentido original que não foi até agora teorizado. (JAMESON, 1997: 74)

Ou seja, a esfera cultural perde sua autonomia e sofre uma hipertrofia a ponto de penetrar todo o social. O exercício cotidiano de autorreflexão do sujeito através da cultura acontece de fato, embora submetido ao exercício de uma racionalidade instrumental orientada a partir das determinações do mercado (enquanto limites, ou determinações negativas) e dos seus agentes (enquanto atos e pressões sociais, ou determinações positivas). Essa perda de autonomia guarda relação com a "morte", ou descentramento, do sujeito, em que "o sujeito centrado que existia na época do capitalismo clássico e da família nuclear foi dissolvido no mundo da burocracia organizacional" (JAMESON, 1997: 42). Ele sofria as agonias do novo mundo moderno e era subordinado a todo tipo de sentimento daí derivado. O pós-modernismo, contudo, ao descentralizá-lo, poupa-o desses sentimentos, provocando o que Jameson (1997: 43) chama de esmaecimento dos afetos. Assim, os produtos culturais pós-modernos estão imbuídos de sentimentos 
"autossustentados e impessoais". Disso decorre "a crescente inviabilidade de um estilo pessoal" e "a prática quase universal em nossos dias do que pode ser chamado de pastiche" (JAMESON, 1997: 43, grifo nosso).

Pastiche é um conceito que, em um contexto permeado pela impessoalidade ao qual o pós-modernismo nos atira, pode ser entendido como um recurso através do qual o sujeito tenta lidar com os dilemas do contemporâneo. Segundo Jameson (2001: 101), ele pode ser sintetizado como

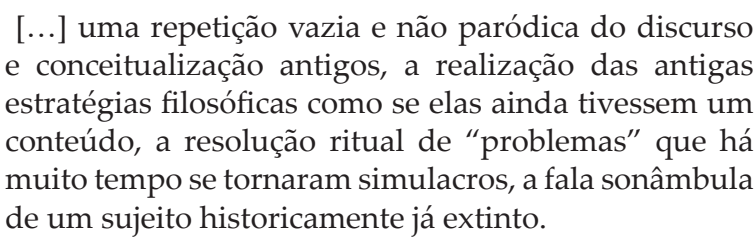

O pós-modernismo, portanto, não ofereceria condições para o surgimento de novas formas para pensar os problemas contemporâneos, dado o processo de fragmentação que sofre o sujeito ${ }^{10}$, de modo que o mesmo se vê obrigado a buscar essas formas no passado. Isso quer dizer que o "novo" que reveste o pós-modernismo não passaria de pastiches de ideias cujas raízes materiais se acham arraigadas em outro momento histórico:

\footnotetext{
${ }^{10}$ Jameson (1997: 40) afirma que na cultura pós-moderna, com a crítica pósestruturalista da hermenêutica, o chamado "modelo de profundidade" é atacado. A teoria contemporânea teria repudiado, além do modelo hermenêutico do fora e do dentro deduzido de "O grito" de Edvard Munch, o 1 - modelo dialético da essência e da aparência; o 2 - modelo freudiano do latente e do manifesto; o 3 - modelo existencialista, da autenticidade e inautenticidade; e, por fim, o 4 - da semiótica, que guarda a oposição entre significante e significado. Com esse repúdio, a teoria contemporânea colocara em voga "uma concepção de práticas, discursos e jogos textuais", na qual "a profundidade é substituída pela superfície, ou por superfícies múltiplas" (JAMESON, 1997: 40); daí a fragmentação da percepção do sujeito e a complexificação do exercício de uma reflexão diagnóstica do seu meio.
}

Idéias - Rev. Inst. Filos. Ciênc. Hum. UNICAMP, v.7, n.1, p. 227-248, jan/jul. 2016 
é assim que os pós-modernos teriam inventado o contemporâneo a partir das percepções passadas. As formas passadas se mantém à revelia da essencialidade presente, de modo que as coisas atuais se tornem cópias de algo que, de fato, não existiu - posto que se uma forma passada, expressiva de conteúdos históricos específicos, apresenta uma relação forma/conteúdo $\mathrm{x}$, ao ser tomada como algo independente e aplicada a novos conteúdos, apresenta, então, uma nova relação forma/conteúdo y; essa nova relação forma/ conteúdo é uma cópia aparente na medida em que a persistência da forma simula uma falsa repetição e a percepção dessa repetição leva à crença de que a relação $x$ é igual à $y$, quando de fato são relações diferentes e y não tenha acontecido no passado, apesar da identidade formal - e que a rigor, não existem enquanto atuais - já que a relação forma/conteúdo se torna falsa tão logo se torne assíncrona ${ }^{11}$.

Conforme Jameson (1997: 45):

essa onipresença do pastiche (...) é, ao menos, compatível com a dependência e com o vício - com esse apetite, historicamente original, dos consumidores por um mundo transformado em mera imagem de si próprio, por pseudo-eventos e por espetáculos (o termo utilizado pelos situacionistas). É para esses objetos que devemos reservar a concepção de Platão do simulacro, a cópia idêntica de algo cujo original jamais existiu (grifos nossos).

A espacialidade na sociedade pós-moderna seria, dessa forma, composta pela imagem, e Jameson (1997: 45), ao evocar Debord em "A sociedade do espetáculo", bem lembra que "a imagem

\footnotetext{
${ }^{11}$ Estamos pensando aqui que a "coisa" existe enquanto forma, ou aparência, que se ancora em uma essência. Se a interpretação da "coisa" atual é mediada por uma forma cuja essência é anacrônica, a verdade essencial da "coisa" atual se perde, de modo que, sendo a interpretação reificada, a "coisa" mesma se perde, tornando-se inacessível ao conhecimento e tendo sua própria existência relativizada.
} 
se tornou a forma final da reificação": as imagens se coisificam, constituindo verdades em si e abolindo a noção de que elas são constituídas de reflexos unilaterais e não esgotados da realidade. Através desse processo a imagem relativiza a realidade, a qual se torna superficial e múltipla. Essa "lógica espacial do simulacro" atinge o tempo histórico, fazendo com que o passado, que do ponto de vista de Lukács apresentava-se como "uma genealogia orgânica de um projeto burguês coletivo", se transforme "em uma vasta coleção de imagens, um enorme simulacro fotográfico" (JAMESON, 1997: 45). Nesse sentido podem ser pensados os chamados "filmes de nostalgia" que, através de um processo de colonização estética de épocas passadas, recriam o passado de modo "intertextual" segundo as diversas apropriações estéticas possíveis, e trazem à tona o problema da incompatibilidade dessa linguagem - cinematográfica, ou de modo mais geral, artística com a "historicidade genuína".

Assim, "a história dos estilos estéticos desloca a história real'" (JAMESON, 1997: 47), ou seja, ressignifica as formas passadas ao acessá-las por meio de códigos estéticos colonizados pelo pensamento contemporâneo, os quais, por não serem problematizados do ponto de vista de uma relação forma/conteúdo em perspectiva histórica, oferece um acesso carente de mediações que conectem as formas aos conteúdos que a geraram. A partir disso podemos pensar que, sem essas mediações necessárias à concatenação das formas aos seus conteúdos, o passado - ou o conjunto de formas sociais, políticas, estéticas, etc. que tornam os acontecimentos passados acessíveis e apreensíveis pelo intelecto - enquanto elemento "referente" para a compreensão do presente e proposição para o futuro se torna "inválido". Ou seja, na realidade e por mais que sua aparência sugira o contrário, são formas passadas ressignificadas no presente, ideológicas e reificadas que se constituem em referente quando se olha para o passado ou quando se imagina o futuro. Nesse sentido, a capacidade de gerar utopias fica comprometida pelo fetichismo presente na mercadoria e por sua lógica auto reprodutiva. 
Esse problema da temporalidade fica mais claro a partir da noção lacaniana de esquizofrenia, que, no plano linguístico, aponta para uma "ruptura na cadeia dos significantes, isto é, as séries sintagmáticas encadeadas de significantes que constituem um enunciado ou um significado" (JAMESON, 1997: 53). O significado - "o sentido ou o conteúdo conceitual de uma enunciação" - é entendido como o resultado do movimento do significante ao significado, ou seja, resulta de uma relação ordenada entre os significantes. Dessa forma, o significado é entendido, objetivamente, não em si, mas

[...] como um efeito-de-significado, como a miragem objetiva da significação gerada e projetada pela relação interna dos significantes. Quando essa relação se rompe, quando se quebram as cadeias da significação, então temos a esquizofrenia sob a forma de um amontoado de significantes distintos e não relacionados. (JAMESON, 1997: 53)

No estado esquizofrênico - do ponto de vista linguístico perde-se o sentido que relaciona as coisas, de modo que elas se apresentem esparsas, fragmentadas e sem unidade, qual um vaso quebrado, cuja forma é dada por estilhaços de cerâmica espalhados desordenadamente sobre uma superfície. Para entender de que modo se dá a conexão entre essa "disfunção linguística e a psique do esquizofrênico", Jameson (1997: 53) faz uma proposição de dois níveis:

[...] primeiro, a identidade pessoal é, em si mesma, efeito de uma certa unificação temporal entre o presente, o passado e o futuro da pessoa; em segundo lugar, essa própria unificação temporal ativa é uma função da linguagem, ou melhor, da sentença, na medida em que esta se move no tempo, ao redor do seu círculo hermenêutico. 
Portanto, a incapacidade de dar unidade à temporalidade da sentença - passado, presente, futuro - no plano linguístico, significa a incapacidade de realizar essa mesma unidade no plano da experiência biográfica. Assim, Jameson (1997: 54) utiliza essa discussão sobre esquizofrenia para compreender a sociedade pós-moderna, na qual "a ruptura da temporalidade libera, repentinamente, esse presente do tempo de todas as atividades e intencionalidades que possam focalizá-lo e torná-lo um espaço de práxis $[\ldots . . .]^{\prime \prime}$. O sujeito é invadido violentamente pelo presente, apreendendo isolada e imediatamente o significante, o que tolhe sua percepção do passado, bem como sua capacidade em pensar o futuro. Nesse processo, o sujeito perde a capacidade de pensar a utopia, uma vez que ela exige uma percepção que capte não só as propriedades da coisa, mas o sentido dessas propriedades e as suas tendências futuras.

Daí se observar um "engessamento" da crítica em propor mudanças de sentido emancipatório. Jameson (2005: xii) aponta na introdução de "Archaeologies of the future" que, para além de haver inimigos ou obstáculos que impedem uma transformação social radical, há uma "crença universal" de que, não só a tendência que vivemos atualmente de aprofundamento da dominação é "irreversível", como as alternativas históricas ao capitalismo se mostraram inviáveis e impossíveis. Ou seja, haveria um sentimento geral de que o cotidiano, entendendo o presente por seu fundamento, seria a categoria na qual se esgotam as possibilidades de transformação. As pequenas e constantes inovações estéticas do dia-a-dia se apresentam, assim, como pequenas "revoluções" ou rupturas significativas com o velho e alianças emancipatórias com o novo. Elas nos dão a impressão de que o cotidiano "caminha", se move em direção ao novo. Mas se a impressão do movimento é real, é possível que seu deslocamento não seja, de modo que esse movimento possa ser comparado a uma roda que gira em falso em torno do próprio eixo. Isso porque aqueles elementos que são objetos de inovação e experimentação são também elementos de 
dinamização do ciclo de realização das mercadorias - compra e venda -, cujo resultado é a conservação do modelo vigente.

Diante de um sistema social que, embora apresente possibilidades de transformação, esteriliza de modo sutil a agência revolucionária dos sujeitos a partir dos elementos que foram discutidos acima, libertar o pensamento do presente superficial se apresenta como uma alternativa emancipatória. Daí a importância da utopia para Jameson, cujo sentido é sintetizado por Cevasco (2007: 123) em resenha sobre o "Archaeolgies of the future":

[...] utopias são definidas no livro como um experimento de pensamento que tenta resolver um problema através do poder da imaginação. Esses experimentos são usados para tentar entender algo prático através de uma analogia. É claro que as utopias constituem exatamente um experimento de pensamento, no qual elas fornecem uma variação experimental sobre o nosso universo empírico (tradução nossa).

Cevasco (2007: 126) aponta, ainda, que a utopia, na leitura de Jameson, não sucumbe à tentação de dar soluções, que historicamente não existem posto a atualidade dos problemas, mas aponta que a contradição é sua estrutura central. Ou seja, o próprio fato de Jameson declarar, com seu trabalho, a dialética como forma e método vigente de funcionamento e apreensão da sociedade é algo que em si mesmo procede do utópico, posto que entende a dialética como a unidade do contraditório e, como tal, carrega em si um processo de mudança necessário e inédito. Se quando se pensam alternativas emancipatórias todas as possibilidades parecem estar estagnadas, aparência essa cujo mérito pertence à ideologia, então o exercício de imaginar o novo é fundamental. Evidentemente, esse exercício deve ser algo crítico na medida em que não toma pra si os simulacros cedidos pelo pós-modernismo para compreender o real. Apesar de não serem normativos, os escritos de Jameson sugerem que se pensem as utopias a fim de que a dominação seja superada: uma crítica negativa do pós- 
modernismo, como faz Jameson nos textos aqui abordados, é um trecho necessário para se alcançar esse caminho emancipatório.

\section{Conclusão}

Através dessa rápida e não exaustiva incursão na crítica de Jameson ao assim chamado pós-modernismo é possível notar a fertilidade da matriz teórica marxista (notadamente pelo seu trato específico com a dialética), inclusive para temas que não aparecem de forma marcante nas elaborações teóricas constitutivas dessa matriz. Destaca-se o fato da crítica jamesoniana ter conseguido integrar outros elementos teóricos à tradição marxista em geral e à do "marxismo ocidental" em particular, o que demonstra, além da originalidade do autor em questão, a capacidade e possibilidade dessa matriz teórica ser sempre repensada em função do objeto de análise, já que nessa tradição se propugna que o método seja imanente ao objeto e, portanto, dele dependente. Disso decorreu, por exemplo, a necessidade de se rever a ideia de determinação, como realizou Williams (1979), bem como de se por em dúvida alguns posicionamentos já naturalizados dentro do marxismo, como a concepção da economia enquanto esfera que esgotaria, por si, a análise social.

A partir das tentativas de submeter a cultura à análise marxista, fica claro também, para essa perspectiva, o ganho analítico, do ponto de vista da sua capacidade inventiva, proporcionado pela busca de uma visão total da sociedade. Dessa maneira, Jameson consegue colocar o pós-modernismo sob uma análise totalizante, de modo a situá-lo como resultado de uma expansão da esfera cultural para todos os domínios da vida social, a qual levou consigo a lógica da mercadoria. Nesse sentido, as chamadas "cultura de massa" e "alta cultura" aparecem como momentos constitutivos de uma unidade contraditória, na qual a emancipação está inscrita. Para acessá-la, o autor sugere a via da utopia, um pensar para além do sensível e a partir dele. As possibilidades emancipatórias se diluem pela sociedade na mesma medida da expansão da cultura. 
Isso põe em questão tanto as ideias de revolução/emancipação e de sujeito revolucionário quanto abre novas perspectivas em relação à forma da práxis revolucionária.Apesar de faltar vários elementos e discussões teóricas para construir um caminho mais concreto até o pensamento de Jameson - o que demandaria um trabalho de maior fôlego cuja finalidade principal fosse essa construção é possível vislumbrar, ainda que em esboço, a análise jamesoniana enquanto um resultado do desdobramento dos momentos de um movimento teórico realizado dentro de um marxismo preocupado com a questão da cultura. Nesse sentido, a "cultura" do marxismo - ou seja, o seu "mainstream" economicista ou politicista - cede espaço a um marxismo da cultura. Jameson encarna, dessa forma, uma possibilidade - dentre outras - de uma crítica social da cultura contemporânea e de uma crítica cultural da sociedade contemporânea a partir dos marcos teóricos estabelecidos por Marx e Engels.

\section{Referências}

ADORNO, T. W.; HORKHEIMER, M. [1944] Dialética do esclarecimento. Rio de Janeiro: Zahar Editores, 2006.

ANDERSON, P. Considerações sobre o marxismo ocidental. Porto: Afrontamento, 1976.

CAMARGO, S. C. Modernidade e dominação: Theodor Adorno e a teoria social contemporânea. São Paulo: Annablume, 2006.

CEVASCO, M. E. Archaeologies of the future: western Marxism revisits Utopia, Situations: Project of the radical imagination, v. 2, n. 1, ano 2007, pp. 121-126. Disponível em: <http://goo.gl/ gW8VoM>. Acesso em nov. 2014.

DEBORD, G. Manifesto internacional situacionista. Disponível em: <http://goo.gl/WnsKuJ>. Acesso em: 1 jul. 2015. 
JAMESON, F. [1979]. Reificação e utopia na cultura de massas. In: JAMESON, F. As marcas do visível. Rio de Janeiro: Graal, 1995.

JAMESON, F. [1991]. Pós-modernismo: a lógica cultural do capitalismo tardio. 2. ed. São Paulo: Editora Ática, 1997.

JAMESON, F. [1997]. Transformações da imagem na pósmodernidade. In: JAMESON, F. A cultura do dinheiro: ensaios sobre a globalização. 2. ed. Petrópolis: Editora Vozes, 2001.

JAMESON, F. Archaeologies of the future: the desire called Utopia and other science fictions. New York: Verso, 2005.

LUKÁCS, G. [1963]. Introdução à estética marxista. Rio de Janeiro: Civilização Brasileira, 1968.

LUKÁCS, G. [1976]. Para uma ontologia do ser social. São Paulo: Boitempo, 2012.

MANDEL, E. [1972]. O capitalismo tardio. São Paulo: Abril Cultural, 1982.

MARX, K. [1859]. O "prefácio" da Contribuição à Crítica da Economia Política. In: Ianni, Octavio. Marx: Sociologia. São Paulo: Editora Ática, 1988.

MARX, K. [1859]. Zur Kritik der politischen Ökonomie. In: Marx, K.; ENGELS, F. Werke. 13. Bd. 7. Aufl. Berlin: Dietz Verlag, 1971.

MARX, K. [1867]. O Capital: crítica da economia política. São Paulo: Nova Cultural, 1985.

POLLOCK, F. State capitalism: its possibilities and limitations. In: ARATO, A.; GEBHARDT, E. (org). The essential Frankfurt School reader. New York: Continuum, 1990.

SINGER, Paul. Apresentação. In: MANDEL, E. [1972]. O capitalismo tardio. São Paulo: Abril Cultural, 1982.

WILLIAMS, R. [1977]. Marxismo e literatura. Rio de Janeiro: Zahar Editores, 1979. 
